\title{
Magnetic resonance imaging study cannot individually distinguish individuals with mild cognitive impairment, mild Alzheimer's disease, and normal aging
}

Estudo por ressonância magnética não pode diferenciar individualmente os indivíduos com declínio cognitivo leve, doença de Alzheimer leve e envelhecimento normal

Terce Liana Menezes, Luciana Patrízia A. Andrade-Valença, Marcelo Moraes Valença

\begin{abstract}
Objective: To evaluate the volumetric and spectroscopy aspects of hippocampus in patients with mild Alzheimer's disease (AD) and mild cognitive impairment (MCl). Methods: A series of patients older than 65 years and with memory deficit were studied. Results: The evocation of words test presented a significant reduction in the number of words recalled by the patients with $\mathrm{MCl}$ and mild $\mathrm{AD}$ as compared with the control group. Bilateral reduction of the hippocampus volume in the AD group was observed when compared to the control group. There were no statistical differences in the values of $\mathrm{NAA} / \mathrm{Cr}, \mathrm{ml} / \mathrm{Cr}$, $\mathrm{Cho} / \mathrm{Cr}$ and $\mathrm{ml} / \mathrm{NAA}$ between the groups. Conclusions: Magnetic resonance imaging study failed to individually distinguish patients with $\mathrm{MCl}$, mild $\mathrm{AD}$ and normal aging. However, patients with mild AD presented loss of asymmetry between the right and left hippocampus, and a reduction in hippocampus volume.
\end{abstract}

Key words: Alzheimer disease, dementia, mild cognitive impairment, hippocampus, magnetic resonance imaging, spectroscopy.

\section{RESUMO}

Objetivo: Avaliar volume e espectroscopia do hipocampo em pacientes com doença de Alzheimer leve e declínio cognitivo leve. Métodos: Foi estudada uma série de pacientes com 65 anos de idade ou mais, com déficit de memória. Resultados: 0 teste de evocação de palavras mostrou redução significativa no número de palavras lembradas pelos pacientes com declínio cognitivo leve e doença de Alzheimer leve, em comparação com o grupo controle. Foi observada redução bilateral do volume do hipocampo no grupo com doença de Alzheimer quando comparado com o grupo controle. Não houve diferença estatística nos valores de NAA/Cr, ml/Cr, Cho/Cr e ml/NAA entre os grupos. Conclusão: Estudo pela ressonância magnética não diferencia individualmente os pacientes com declínio cognitivo leve, doença de Alzheimer leve e envelhecimento normal. No entanto, pacientes com quadro leve de doença de Alzheimer apresentam perda de assimetria entre os hipocampos direito e esquerdo e redução no volume do hipocampo.

Palavras-Chave: doença de Alzheimer, demência, comprometimento cognitivo leve, hipocampo, ressonância magnética, espectroscopia.

Elderly individuals with mild cognitive impairment (MCI) are part of a continuum between normal aging with its cognitive difficulties and fully-fledged dementia. However, there is a growing body of evidence suggesting that MCI might precede the onset of Alzheimer's disease (AD). Longitudinal studies have demonstrated that subjects with MCI present a progression rate of $10-15 \%$ per year to $\mathrm{AD}$, contrasting with $1-2 \%$, in a similar analysis, in the general population using a similar age range ${ }^{1}$.

Declarative memory is related to the involvement of mesial structures of the temporal lobe, especially the hippocampus ${ }^{2,3}$. Studies using magnetic resonance imaging (MRI) may provide in vivo analysis of specific regions of the temporal lobe showing a strong correlation between abnormal neuroimaging findings and the scores obtained on cognitive tests ${ }^{4,5}$. A number of authors have reported that volumetric-structural study and spectroscopy analysis might be useful in the investigation of patients with $\mathrm{MCI}$ in order to diagnose patients with a higher risk of developing $\mathrm{AD}^{6-8}$.

In advanced phases of $\mathrm{AD}$, major hippocampus atrophy with a decrease in $\mathrm{N}$-acetyl aspartate (NAA) and an increase

MD, PhD; Neurology and Neurosurgery Unit, Department of Neuropsychiatry, Federal University of Pernambuco, Recife, Brazil.

Correspondence: Marcelo M. Valença; Neurology and Neurosurgery Unit, Department of Neuropsychiatry, Federal University of Pernambuco; Cidade

Universitária; 50670-420 Recife PE-Brasil; E-mail:mmvalenca@yahoo.com.br

Conflict of interest: There is no conflict of interest to declare.

Received 11 March 2012; Received in final form 22 October 2012; Accepted 30 October 2012. 
in mio-inositol (mI) is a common finding ${ }^{7,9}$. Furthermore, the reduction in the concentration of NAA is inversely proportional to the number of senile plaques ${ }^{10}$.

Studies during mild or initial stages of $\mathrm{AD}$ show that the MRI alterations are discrete, and some have reported controversial results regarding the expected reduction in hippocampus volume ${ }^{11-16}$ and the changes in proton spectroscopy parameters $^{7,17-21}$. This controversy has stimulated new studies aimed at a more precise differential diagnosis between: (a) patients with MCI, (b) patients with MCI as a preclinical form of $\mathrm{AD}$, and (c) patients at the initial stage of $\mathrm{AD}$.

This study was performed with the aim of investigating patients with $\mathrm{MCI}$ and mild $\mathrm{AD}$ using volumetric-structural $\mathrm{MRI}$ and spectroscopy analysis, to evaluate volumetric analysis of the hippocampus and possible alterations in NAA, mI and choline (Cho) in the hippocampus.

\section{METHODS}

We studied a series of 22 right-handed patients over 65 years of age, with memory deficit complaints, evaluated for the first time during the years of 2002 and 2003 at the Cognitive Neurology Unit, Federal University of Pernambuco Hospital, comprising 11 patients with MCI and 11 with mild $\mathrm{AD}$, based on NINCDS-ADRDA ${ }^{22}$. Patients with mild $\mathrm{AD}$ scored 1 in the Clinical Dementia Rating $(\mathrm{CDR})^{23}$. To evaluate the staging severity of de cognitive deficit, CDR score of 0.5 was used for MCI patients whose cognitive deficit was not severe enough to interfere with the day-to-day life and usual activities. The $\mathrm{AD}$ patients presented memory impairment associated with one or more cognitive disorders such as dysphasia, apraxia, agnosia or disturbance in executive functioning; progressive social or occupational impairment and a clear decline from previous level of functioning and reported continuing cognitive decline. No specific treatment for the cognitive impairment was used until after the MRI evaluation.

Patients with moderate/severe $\mathrm{AD}$ stages and those with previous chronic/degenerative or psychiatric disorders and those on neuropsychiatry medication were excluded. The control group consisted of 15 healthy subjects, also over 65 years of age.

All the participants (or their legal representative) gave their formal written consent. The research protocol was approved by the Ethics Committee of the Federal University of Pernambuco.

\section{Acquisition and analysis of MRI}

MRI was performed using a Magnetom Sonata 1.5 Tesla (Siemens). The clinical profile of the patient was unknown to the examiner during the analysis of the MRI data.

We used a volumetric sequence with images in T1, MP-RAGE (time repetition, TR=9.7 ms; echo time, ET=4 ms; inclination angulations $12^{\circ}$ ), matrix of 256x128 mm, vision range of $200 \mathrm{~mm}$, with coronal sections $3 \mathrm{~mm}$ thick obtained perpendicularly to the longer axis of the hippocampus. A sequence with approximately 12 to 15 slices across the entire extension of the hippocampus was obtained ${ }^{24}$.

Hippocampal atrophy was considered when the volume was smaller than the mean minus two standard deviations (mean - 2SD), calculated using the data of the control group ${ }^{11}$.

The experimental parameters of MRI used were a STEAM sequence (ET=20 ms; TR=1.500 ms; number of acquisitions=128).

The major photonic resonance was identified and read from right to left: (a) NAA (2.03 ppm); (b) creatine (Cr, $3.03 \mathrm{ppm}$ ); (c) Cho (3.23 ppm); (d) mio-inositol (mI) (3.56 ppm). The ratios of NAA/Cr, mI/Cr, Cho/Cr, mI/Cr and $\mathrm{mI} / \mathrm{NAA}$ were analyzed.

\section{RESULTS}

The individual data are shown in Table 1. Table 2 shows demographic variables, the total Mini-Mental State Examination (MMSE) scores, and the results of the evocation of words test in the three evaluated groups. The statistical analysis did not show any significant differences between genders and educational background. Regarding age, there was a significant difference $(p<0.05)$ between the control group and the group with mild $\mathrm{AD}$, but there were no statistical differences between the control group and the group with MCI. There were also statistical differences between ages, when the $\mathrm{MCI}$ and the $\mathrm{AD}$ groups were compared ( $\mathrm{p}=0.0451$, Mann-Whitney test).

The total MMSE scores obtained for MCI and AD significantly decreased compared with the control group $(\mathrm{p}<0.05)$. The word evocation test presented a significant reduction in the number of words recalled by the patients with MCI $(3.3 \pm 1.2 ; \mathrm{p}<0.01)$ and with mild $\mathrm{AD}(0.9 \pm 0.9$; $\mathrm{p}<0.001)$ as compared to the control group (7.6 \pm 1.4$)$. There was also a statistical difference between the groups with MCI and mild $\mathrm{AD}$ ( $\mathrm{p}=0.0013$, Mann-Whitney test).

\section{Volumetric study of hippocampus}

Both groups presented a smaller volume of the left hippocampus, when compared with the contralateral right hippocampus $(p=0.0049$, Wilcoxon paired test). Patients with mild $\mathrm{AD}$ presented no significant differences between the right and left hippocampi. Regarding the control group values, hippocampal atrophy was considered to be present when the right hippocampus was smaller than $1.67 \mathrm{~cm}^{3}$ and the left hippocampus smaller than $1.58 \mathrm{~cm}^{3}$. Using this criterion, it was observed that only one of the patients with mild $\mathrm{AD}$ presented bilateral hippocampal atrophy (patient \#10 in Table 1, right $1.20 \mathrm{~cm}^{3}$ and left $1.18 \mathrm{~cm}^{3}$ ).

Figure shows a bilateral reduction of the hippocampus volume in the $\mathrm{AD}$ group as compared to the control group (right side: $2.08 \pm 0.42 \mathrm{~cm}^{3}$ versus $2.61 \pm 0.47 \mathrm{~cm}^{3}$, respectively; left side: $1.96 \pm 0.39 \mathrm{~cm}^{3}$ versus $2.46 \pm 0.44 \mathrm{~cm}^{3}$, respectively; $\mathrm{p}<0.05$ ). 
Table 1. Individual data obtained in the control, mild cognitive impairment and mild Alzheimer's disease groups.

\begin{tabular}{|c|c|c|c|c|c|c|c|c|c|c|c|}
\hline \multirow{2}{*}{ Pacient \# } & \multirow{2}{*}{$\begin{array}{c}\text { Age } \\
\text { (years) }\end{array}$} & \multirow{2}{*}{ Gender } & \multirow{2}{*}{$\begin{array}{l}\text { Schooling } \\
\text { (years) }\end{array}$} & \multirow{2}{*}{$\begin{array}{l}\text { MMSE } \\
(0-30)\end{array}$} & \multirow{2}{*}{$\begin{array}{l}\text { Word } \\
\text { evocation } \\
(0-10)\end{array}$} & \multicolumn{2}{|c|}{ Hippocampal volume $\left(\mathrm{cm}^{3}\right)$} & \multicolumn{2}{|c|}{$\mathrm{NAA} / \mathrm{Cr}$} & \multicolumn{2}{|c|}{$\mathrm{ml} / \mathrm{Cr}$} \\
\hline & & & & & & Right & Left & Right & Left & Right & Left \\
\hline \multicolumn{12}{|c|}{ CONTROL GROUP } \\
\hline 1 & 68 & $\mathrm{~F}$ & 8 & 26 & 6 & 3.21 & 2.52 & 1.34 & 1.28 & 0.86 & 0.59 \\
\hline 2 & 69 & $\mathrm{~F}$ & 8 & 29 & 7 & 2.07 & 2.24 & 1.38 & 1.31 & 0.75 & 0.83 \\
\hline 3 & 74 & $\mathrm{~F}$ & 8 & 29 & 8 & 2.30 & 2.20 & 1.27 & 1.42 & 0.52 & 0.92 \\
\hline 4 & 70 & $\mathrm{~F}$ & 9 & 28 & 7 & 2.46 & 2.34 & 1.80 & 1.35 & 0.65 & 1.40 \\
\hline 5 & 73 & $\mathrm{~F}$ & 9 & 29 & 6 & 2.53 & 2.42 & 1.25 & 1.31 & 0.66 & 0.69 \\
\hline 6 & 78 & $\mathrm{~F}$ & 9 & 29 & 9 & 2.85 & 2.85 & 1.60 & 1.17 & 0.84 & 0.81 \\
\hline 7 & 67 & $\mathrm{~F}$ & 12 & 29 & 6 & 2.21 & 2.10 & - & - & 1.08 & 0.52 \\
\hline 8 & 67 & $\mathrm{~F}$ & 12 & 30 & 6 & 2.28 & 2.07 & 2.26 & 1.67 & 1.16 & 0.78 \\
\hline 9 & 69 & $F$ & 16 & 30 & 10 & 2.45 & 2.11 & 1.20 & 1.11 & 0.63 & 0.74 \\
\hline 10 & 72 & $M$ & 16 & 30 & 9 & 2.64 & 2.12 & 1.21 & 1.13 & 1.17 & 1.07 \\
\hline 11 & 73 & $M$ & 16 & 30 & 6 & 3.35 & 3.07 & 1.07 & 1.50 & 1.07 & 1.19 \\
\hline 12 & 66 & $F$ & 12 & 29 & 9 & 3.56 & 3.59 & 1.34 & 1.23 & 0.84 & 0.66 \\
\hline 13 & 83 & $F$ & 9 & 30 & 9 & 2.82 & 2.70 & 1.38 & 1.36 & 0.83 & 0.89 \\
\hline 14 & 67 & $F$ & 16 & 29 & 8 & 1.96 & 1.99 & 1.24 & 1.35 & 0.59 & 0.68 \\
\hline 15 & 74 & $M$ & 16 & 28 & 8 & 2.38 & 2.59 & 0.95 & 1.43 & 0.79 & 1.00 \\
\hline \multicolumn{12}{|c|}{ MILD COGNITIVE IMPAIRMENT } \\
\hline 1 & 68 & $\mathrm{~F}$ & 9 & 27 & 0 & 2.67 & 2.45 & 1.40 & 1.17 & 0.85 & 0.69 \\
\hline 2 & 68 & $\mathrm{~F}$ & 10 & 24 & 3 & 2.21 & 1.92 & 1.29 & 1.29 & 0.97 & 0.93 \\
\hline 3 & 71 & M & 16 & 27 & 3 & 2.67 & 2.07 & 1.95 & 1.69 & 0.65 & 0.85 \\
\hline 4 & 71 & M & 16 & 28 & 3 & 2.16 & 2.08 & 0.85 & 1.16 & 0.38 & 0.77 \\
\hline 5 & 75 & $\mathrm{~F}$ & 9 & 27 & 3 & 3.00 & 2.72 & 1.24 & 1.42 & 0.60 & 0.65 \\
\hline 6 & 72 & $\mathrm{~F}$ & 10 & 28 & 4 & 2.46 & 2.04 & 1.15 & 1.03 & 0.59 & 0.77 \\
\hline 7 & 73 & $F$ & 11 & 28 & 4 & 1.93 & 1.95 & 0.86 & 1.08 & 1.06 & 1.04 \\
\hline 8 & 77 & M & 16 & 28 & 4 & 3.15 & 3.00 & 1.11 & 1.32 & 0.57 & 0.96 \\
\hline 9 & 78 & $\mathrm{~F}$ & 16 & 28 & 4 & 1.85 & 1.91 & 1.06 & 1.13 & 0.56 & 0.74 \\
\hline 10 & 83 & $\mathrm{~F}$ & 8 & 24 & 4 & 2.51 & 2.42 & 1.20 & 1.21 & 0.80 & 0.88 \\
\hline 11 & 75 & $M$ & 16 & 28 & 4 & 2.80 & 2.46 & 1.38 & 1.36 & 0.83 & 0.89 \\
\hline \multicolumn{12}{|c|}{ MILD ALZHEIMER'S DISEASE } \\
\hline 1 & 78 & $\mathrm{~F}$ & 12 & 25 & 0 & 2.43 & 2.67 & 1.29 & 1.56 & 0.86 & 0.63 \\
\hline 2 & 81 & $\mathrm{~F}$ & 8 & 20 & 1 & 1.70 & 1.94 & 1.15 & 0.98 & 0.92 & 0.98 \\
\hline 3 & 87 & $\mathrm{~F}$ & 9 & 18 & 0 & 1.92 & 1.83 & 1.11 & 1.20 & 0.55 & 0.92 \\
\hline 4 & 83 & $\mathrm{~F}$ & 12 & 27 & 3 & 1.82 & 2.00 & 1.80 & 0.52 & 0.60 & 1.03 \\
\hline 5 & 87 & $\mathrm{~F}$ & 12 & 26 & 2 & 1.97 & 1.76 & 1.24 & 1.17 & 1.00 & 0.71 \\
\hline 6 & 66 & $F$ & 12 & 19 & 1 & 2.41 & 2.28 & 1.00 & 1.31 & 1.05 & 1.00 \\
\hline 7 & 83 & $M$ & 16 & 27 & 1 & 2.57 & 2.25 & 0.86 & 1.16 & 0.38 & 0.77 \\
\hline 8 & 69 & $F$ & 16 & 22 & 0 & 2.04 & 1.81 & 1.29 & 1.44 & 0.55 & 0.81 \\
\hline 9 & 74 & $F$ & 12 & 27 & 1 & 2.29 & 2.18 & 1.26 & 0.90 & 0.63 & 0.74 \\
\hline 10 & 85 & $\mathrm{~F}$ & 12 & 22 & 0 & 1.20 & 1.18 & 1.95 & 1.21 & 0.86 & 1.06 \\
\hline 11 & 79 & $F$ & 8 & 23 & 1 & 2.52 & 1.65 & 1.23 & 1.38 & 0.57 & 0.72 \\
\hline
\end{tabular}

MMSE: Mini-Mental State Examination; NAA: N-acetyl aspartate; Cr: creatine; ml: mio-inositol.

The left and right hippocampi of the group with mild $\mathrm{AD}$ presented reductions of 20.3 and $20.3 \%$, respectively, compared with the control group. There was no statistically significant difference between groups.

\section{Proton spectroscopy of hippocampus}

There were no statistical differences in the values of $\mathrm{NAA} / \mathrm{Cr}, \mathrm{mI} / \mathrm{Cr}, \mathrm{Cho} / \mathrm{Cr}$ and $\mathrm{mI} / \mathrm{NAA}$ between the right and left hippocampi in each group or between the groups themselves (Tables 3 and 4).

\section{DISCUSSION}

Patients with $\mathrm{MCI}$ and mild $\mathrm{AD}$ displayed an involvement of declarative memory, which suggests a progressive degenerative process.

Similar studies showed great discrepancy in sensitivity and specificity regarding the determination of hippocampus volumetry ${ }^{11,14,25}$. The inclusion of patients in moderate and advanced phases might have contributed to the clear presence of hippocampus atrophy previously reported ${ }^{25}$. 
right hippocampus
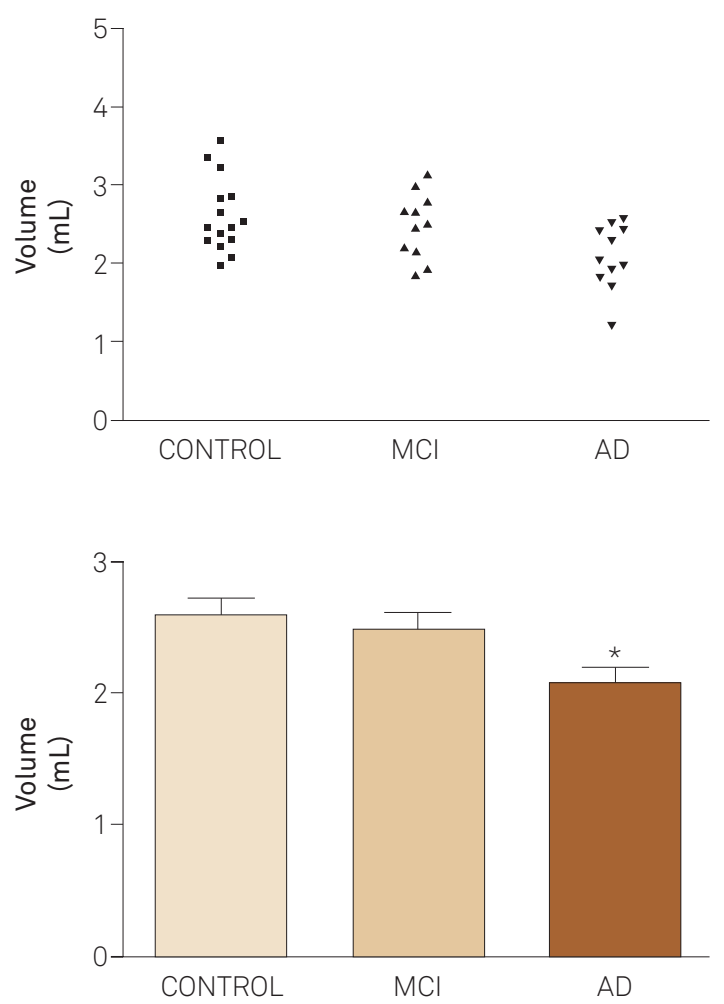

left hippocampus
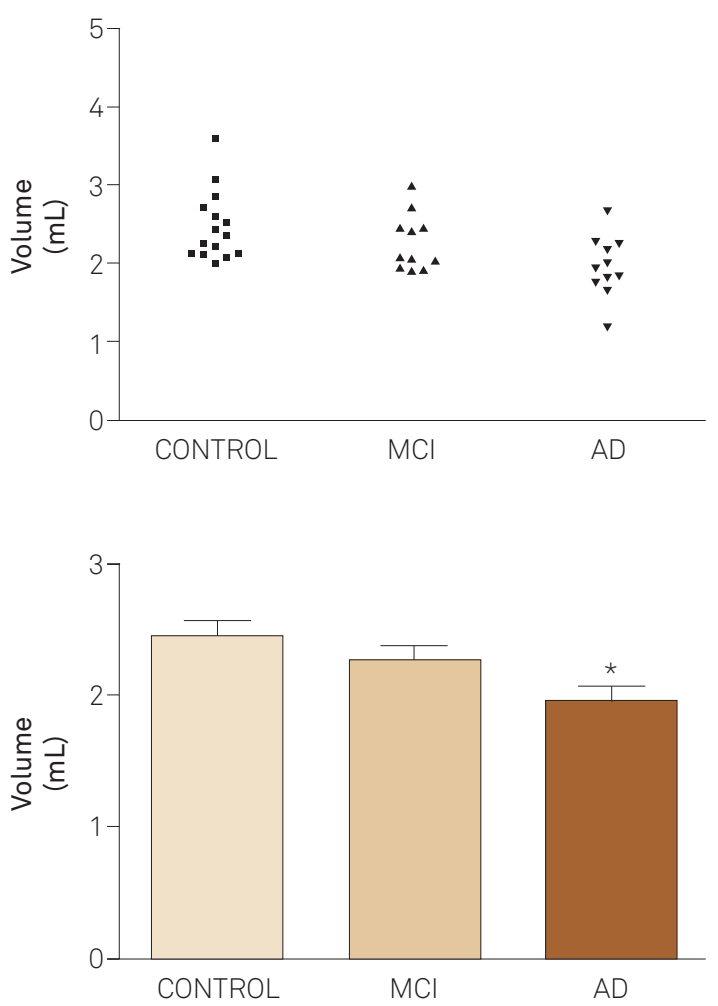

* $\mathrm{p}<0.05$ versus control group.

Figure. Right and left hippocampal volumes observed in the control, mild cognitive impairment (MCl), and mild Alzheimer's disease (AD) groups. The upper panels show individual values and in the lower panels data are shown as means \pm standard error of the mean (SEM) in the respective groups.

Table 2. Demographic characteristics and the scores on the Mini-Mental State Examination (MMSE) and number of words recalled in the control, mild cognitive impairment $(\mathrm{MCl})$ and mild Alzheimer's disease (AD) groups.

\begin{tabular}{lccc} 
& Control $(\mathrm{n}=15)$ & $\mathrm{MCl}(\mathrm{n}=11)$ & $\mathrm{AD}(\mathrm{n}=11)$ \\
Age (years) & $71 \pm 5$ & $74 \pm 5$ & $79 \pm 7^{\mathrm{a}, \mathrm{b}}$ \\
Gender (man) & $3 / 15(20 \%)$ & $4 / 11(36 \%)$ & $1 / 11(9 \%)$ \\
Schooling (years) & $12 \pm 3$ & $13 \pm 4$ & $12 \pm 3$ \\
MMSE (0-30) & $29 \pm 1$ & $27 \pm 2^{\mathrm{a}}$ & $24 \pm 4^{\mathrm{a}, \mathrm{b}}$ \\
Word evocation & $7.6 \pm 1.4$ & $3.3 \pm 1.2^{\mathrm{a}}$ & $0.9 \pm 0.9^{\mathrm{a}, \mathrm{b}}$ \\
\hline
\end{tabular}

${ }^{a} p<0.05$ versus control (Dunn's test); p $p<0.05$ versus $\mathrm{MCl}$ (Mann-Whitney's test)

Our study showed that the right hippocampus was larger than the left one in the control group, thus confirming previous reports $^{26}$. The group with MCI maintained asymmetry of volume between the right and left hippocampi, as did the control group.

The comparison of hippocampal volume between the three groups in this study demonstrated that the patients with mild $\mathrm{AD}$ presented a bilateral decrease in volume, although the majority (91\%) still did not present significant hippocampus atrophy, when studied individually, considering the methods employed in the present study. Curiously, Sullivan et al. ${ }^{27}$ reported that the reduction in the gray matter of the temporal lobe related to aging relatively spared the hippocampus in a study comprising 72 healthy subjects aged between 21 and 70 years.
As far as the patients with MCI are concerned, the results of our study are in agreement with that of Soininen et al. ${ }^{12}$, who studied 16 patients with age-associated memory impairment and did not find any differences in hippocampal volume as compared to a control group. It is important to stress that the concept of age-associated memory impairment differs from MCI, because it is established by comparing the results of memory tests in young adults. Thus, maybe this group of patients is at the lowest level of performance for normal aging. However, other studies have demonstrated that the presence of hippocampus atrophy does not necessarily indicate dementia progression ${ }^{13}$ and that patients with MCI that did not progress to dementia did not present any reduction in hippocampus volume in comparison with controls ${ }^{16}$.

A common limitation is that some neuropsychological tests still lack standard analysis in such disorders. Another important issue is the need of a standard nomenclature for the structural and anatomical limits of the hippocampus in order to better interpret results obtained by various groups of investigators ${ }^{6,11,14}$. Serial longitudinal time measurements of the hippocampus have also been regarded as particularly relevant in this kind of study ${ }^{8}$. However, the use of such long-term measurements is impracticable when the specialist needs to make an accurate diagnosis at the first clinical and neuroradiologic evaluation of the individual with cognitive deficit complaints as was the case in the present series. 
Table 3. Values of NAA/Cr, ml/Cr, Cho/Cr and ml/NAA obtained on proton spectroscopy of hippocampus in control, mild cognitive impairment (MCl), and mild Alzheimer's disease (AD) groups.

\begin{tabular}{lcccccc} 
& \multicolumn{2}{c}{ Control $(n=15)$} & \multicolumn{2}{c}{ MCI $(n=11)$} & \multicolumn{2}{c}{ AD $(n=11)$} \\
\cline { 2 - 7 } & Right & Left & Right & Left & Right & Left \\
\hline NAA/Cr & $1.38 \pm 0.33$ & $1.33 \pm 0.15$ & $1.23 \pm 0.30$ & $1.26 \pm 0.19$ & $1.29 \pm 0.32$ & $1.17 \pm 0.29$ \\
$\mathrm{ml} / \mathrm{Cr}$ & $0.81 \pm 0.20$ & $0.85 \pm 0.24$ & $0.72 \pm 0.20$ & $0.83 \pm 0.12$ & $0.75 \pm 0.23$ & $0.85 \pm 0.14$ \\
$\mathrm{Cho} / \mathrm{Cr}$ & $0.87 \pm 0.18$ & $0.87 \pm 0.14$ & $0.83 \pm 0.16$ & $0.78 \pm 0.15$ & $0.84 \pm 0.13$ & $0.90 \pm 0.14$ \\
$\mathrm{ml} / \mathrm{NAA}$ & $0.61 \pm 0.20$ & $0.64 \pm 0.17$ & $0.61 \pm 0.24$ & $0.68 \pm 0.14$ & $0.61 \pm 0.22$ & $0.70 \pm 0.18$ \\
\hline
\end{tabular}

NAA: N-acetyl aspartate; Cr: creatine; ml: mio-inositol; Cho: choline.

Table 4. Frequency of patients with mild cognitive impairment (MCI) or mild Alzheimer's disease (AD) using different values of the mean $\pm 1.0,1.5$, and 2.0 standard deviations (SD) of each of the hippocampal metabolites analyzed.

\begin{tabular}{|c|c|c|c|c|c|}
\hline \multirow{2}{*}{ Metabolite } & \multirow{2}{*}{ SD } & \multicolumn{2}{|c|}{$\mathrm{MCl}$} & \multicolumn{2}{|c|}{$A D$} \\
\hline & & Right & Left & Right & Left \\
\hline \multirow{3}{*}{$\mathrm{NAA} / \mathrm{Cr}$} & -1.0 & $2 / 11(18 \%)$ & $5 / 11(45 \%)$ & $2 / 11(18 \%)$ & $3 / 11(27 \%)$ \\
\hline & -1.5 & $2 / 11(18 \%)$ & $2 / 11(18 \%)$ & $1 / 11(9 \%)$ & $3 / 11(27 \%)$ \\
\hline & -2.0 & $0 / 11(0 \%)$ & $1 / 11(9 \%)$ & $0 / 11(0 \%)$ & $3 / 11(27 \%)$ \\
\hline \multirow{3}{*}{$\mathrm{ml} / \mathrm{Cr}$} & +1.0 & $1 / 11(9 \%)$ & $0 / 11(0 \%)$ & $0 / 11(0 \%)$ & $0 / 11(0 \%)$ \\
\hline & +1.5 & $0 / 11(0 \%)$ & $0 / 11(0 \%)$ & $0 / 11(0 \%)$ & $0 / 11(0 \%)$ \\
\hline & +2.0 & $0 / 11(0 \%)$ & $0 / 11(0 \%)$ & $0 / 11(0 \%)$ & $0 / 11(0 \%)$ \\
\hline \multirow{3}{*}{$\mathrm{Cho} / \mathrm{Cr}$} & +1.0 & $1 / 11(9 \%)$ & $1 / 11(9 \%)$ & $1 / 11(9 \%)$ & $1 / 11(9 \%)$ \\
\hline & +1.5 & $1 / 11(9 \%)$ & $1 / 11(9 \%)$ & $0 / 11(0 \%)$ & $0 / 11(0 \%)$ \\
\hline & +2.0 & $0 / 11(0 \%)$ & $1 / 11(9 \%)$ & $0 / 11(0 \%)$ & $0 / 11(0 \%)$ \\
\hline \multirow{3}{*}{$\mathrm{ml} / \mathrm{NAA}$} & +1.0 & $1 / 11(9 \%)$ & $1 / 11(9 \%)$ & $2 / 11(18 \%)$ & $4 / 11(36 \%)$ \\
\hline & +1.5 & $1 / 11(9 \%)$ & $1 / 11(9 \%)$ & $1 / 11(9 \%)$ & $2 / 11(18 \%)$ \\
\hline & +2.0 & $1 / 11(9 \%)$ & $0 / 11(0 \%)$ & $1 / 11(9 \%)$ & $1 / 11(9 \%)$ \\
\hline
\end{tabular}

NAA: $\mathrm{N}$-acetyl aspartate; Cr: creatine; ml: mio-inositol; Cho: choline.

The ratio value of metabolites $\mathrm{NAA} / \mathrm{Cr}, \mathrm{mI} / \mathrm{Cr}$, $\mathrm{Cho} / \mathrm{Cr}$ and mI/NAA did not show any significant differences between controls vs. MCI or mild $\mathrm{AD}$ patients. Additionally, there was no asymmetry in the metabolic relations between the two hippocampi. Various studies have mentioned the finding of a fall in $\mathrm{NAA} / \mathrm{Cr}^{7,19,20,28}$, with an increase in $\mathrm{mI} / \mathrm{Cr}^{7,19}$, favoring the diagnosis of $\mathrm{AD}$. Some authors report that in the MCI patients there is an initial reduction in the $\mathrm{NAA} / \mathrm{Cr}$ ratio $^{20,21}$. However, others have reported an initial increase in the $\mathrm{mI} / \mathrm{Cr}$ ratio $^{7,18}$.

We conclude that the MRI study failed to individually distinguish patients with $\mathrm{MCI}$, mild $\mathrm{AD}$ and normal aging.
However, if we consider the three groups of patients, the mild $\mathrm{AD}$ ones presented: 1) advanced age; 2 ) lower scores on the MMSE; 3) lower scores on the word evocation test; 4) loss of asymmetry between the right and left hippocampi; and 5) reduction in the volume of the hippocampi.

\section{ACKNOWLEDGMENT}

The authors wish to acknowledge H. Cartaxo, MD and P.B. Santos Filho, PhD, for their help during the volumetric and spectroscopic MRI evaluation.

\section{References}

1. Petersen RC, Smith GE, Waring SC, et al. Mild cognitive impairment: clinical characterization and outcome. Arch Neurol 1999;56:303-308.

2. Squire LR. Memory and the hippocampus: a synthesis from findings with rats, monkeys and humans. Psychol Rev 1992;99:195-231.

3. Rombouts SA, Barkhof F, Veltman DJ, et al. Functional MR imaging in Alzheimer's disease during memory encoding. AJNR Am J Neuroradiol 2000;21:1869-1875

4. Scheltens P, Leys D, Barkhof F, et al. Atrophy of medial temporal lobes on MRI in "probable" Alzheimer's disease and normal ageing: diagnostic value and neuropsychological correlates. J Neurol Neurosurg Psychiatry 1992;55:967-972.

5. Wang $H$, Shu L, Xie J, Zhang H, Zhang D. Diagnostic utility of neuropsychological performance and quantitative MRI-based measurement in Alzheimer's disease. Alzheimer Dis Asssoc Disord 2004:18:163-170.

6. Jack CR Jr, Petersen RC, Xu YC, et al. Medial temporal atrophy on MRI in normal aging and very mild Alzheimer's disease. Neurology 1997;49:786-794.

7. Kantarci K, Jack CR Jr., Xu YC, et al. Regional metabolic patterns in mild cognitive impairment and Alzheimer's disease: a 1HMRS study. Neurology 2000;55:210-217.

8. Metlzer CC. Imaging markers for dementia and neurodegenerative disease. Symposium 2004: Integration of Imaging Strategies in Neuroradiology. ASNR 2004;63-64.

9. Ross BD. The Biochemistry of living tissues: Examination by MRS. NMR Biomed 1991; 4:59-63. 
10. McClure RJ, KanferJN, Panchalingam K, KlunkWE, PettegrewJW. Magnetic resonance spectroscopy and its application to aging and Alzheimer's disease. Neuroimaging Clinics of North American 1995;5:69-87.

11. Jack CR Jr, Petersen RC, O'Brien PC, Tangalos EG. MR-based hippocampal volumetry in the diagnosis of Alzheimer's disease. Neurology 1992;42:183-188.

12. Soininen HS, Partanen K, Pitkänen A, et al. Volumetric analysis of the amygdala and the hippocampus in subjects with age-associated memory impairment: correlation to visual and verbal memory. Neurology 1994;44:1660-1668.

13. Swann A, O'Brien J, Ames D, Schweitzer I, Desmond P, Tress B. Does hippocampal atrophy on MRI predict cognitive decline? Prospective follow-up study. Int J Geriatr Psychiatry 1997;12:1182-1188.

14. Laakso MP, Soininen H, Partanen K, et al. MRI of the hippocampus in Alzheimer's disease: sensitivity, specificity, and analysis of the incorrectly classified subjects. Neurobiol Aging 1998;19:23-31.

15. Petersen RC, Jack CR Jr, Xu YC, et al. Memory and MRI-based hippocampal volumes in aging and AD. Neurology 2000;54:581-587.

16. Chao LL, Schuff N, Kramer JH, et al. Reduced medial temporal lobe $\mathrm{N}$-acetylaspartate in cognitively impaired but non-demented patients. Neurology 2005;64:282-289.

17. Stoppe G, Bruhn H, Pouwels PJ, Hanicke W, Frahm J. Alzheimer disease: absolute quantification of cerebral metabolites in vivo using localized proton magnetic resonance spectroscopy. Alzheimer Dis Assoc Disord 2000;14:112-119.

18. Huang W, Alexander GE, Chang L, et al. Brain metabolite concentration and dementia severity in Alzheimer's disease. Neurology 2001;57:626-632.

19. Martinez-Bisbal MC, Arana E, Marti-Bonmati L, Molla E, Celda B. Cognitive impairment: classification by ${ }^{1} \mathrm{H}$ magnetic resonance spectroscopy. Eur J Neurol 2004;11:187-193.
20. Frederick BD, Lyoo IK, Satlin A, et al. In vivo proton magnetic resonance spectroscopy of the temporal lobe in Alzheimer's disease. Prog Neuropsychopharmacol Biol Psychiatry 2004;28:1313-1322.

21. Chantal S, Braun CM, Bouchard RW, Labelle M, Boulanger Y. Similar $1 \mathrm{H}$ magnetic resonance spectroscopic metabolic pattern in the medial temporal lobes of patients with mild cognitive impairment and Alzheimer disease. Brain Res 2004;1003:26-35.

22. McKhann G, Drachman D, Folstein M, Katzman R, Price D, Stadlan EM. Clinical diagnosis of Alzheimer's disease: report of the NINCDSADRDA work group under the auspices of the Department of Health and Human Services Task Force on Alzheimer's disease. Neurology 1984;34:839-944.

23. Berg L. Clinical Dementia Rating (CDR). Psychopharmacol Bull 1988; 24:637-639.

24. Free SL, Bergin DR, Fish MJ, et al. Methods for normalization of hippocampal volumes measured with magnetic resonance. Am J Neuroradiol 1995;16:637-643.

25. Kesslak JP, Nalcioglu OS, Cotman CW. Quantification of magnetic resonance scans for hippocampal and parahippocampal atrophy in Alzheimer's disease. Neurology 1991;41:51-54.

26. Watson C, Andermann F, Gloor P, et al. Anatomic basis of amygdaloid and hippocampal volume measurement by magnetic resonance imaging. Neurology 1992;42:1743-1750.

27. Sullivan EV, Marsh L, Mathalon DH, Lim KO, Pfefferbaum A. Age-related decline in MRI volumes of temporal lobe gray matter but not hippocampus. Neurobiol Aging 1995;16:591-606.

28. Shiino A, Matsuda M, Morikawa S, Inubushi T, Akiguchi I, Handa J. Proton magnetic resonance spectroscopy with dementia. Surg Neurol 1993;39:143-147. 